\title{
Cytoplasmic-Nuclear Male Sterility: Origin, Evaluation and Utilization
}

\author{
B.V.S. Reddy ${ }^{1}$, K.N. Rai ${ }^{1}$, N.P. Sarma ${ }^{2}$, Ish Kumar $^{3}$, and K.B. Saxena ${ }^{1}$
}

\begin{abstract}
Cytoplasmic-nuclear male sterility (CMS), a potential system for economical hybrid seeds production, results from disharmonious interaction between the cytoplasmic and nuclear genetic factors. Evaluation of CMS system for its utility is determined by many factors. Unstable male sterility increases cost and affects quality of hybrid seed production. Cooler weather during panicle development promotes instability in maize and pigeonpea, high humidity in pearl millet and hot temperature of $42{ }^{\circ} \mathrm{C}$ and above in sorghum. Effect of genetic background of $\mathrm{B}$-lines on male sterility has been found in case of $\mathrm{A}_{1} \mathrm{CMS}$ system in pearl millet and sorghum, and fertility restorer gene expressivity in rice. Maintainer gene frequency in germplasm is another factor to be considered which has bearing on genetic diversification of A-lines. In case of $\mathrm{A}_{1} \mathrm{CMS}$ system in sorghum and pearl millet landraces have greater proportion as restorers. Character association influences the commercial viability of a CMS system. Approaches to estimate the diversity of CMS systems to enhance the exploitation of outstanding inbred lines and also to overcome the risk of disease and pest epidemics, include both traditional field evaluation of hybrids for differential patterns of male fertility restoration and RFLP analysis of mitochondrial DNA. Steps involved in CMS utilization in hybrid cultivar breeding including (i) identification of potential CMS sources, (ii) development of seed parents (A lines) exhibiting complete sterility, (iii) maintenance of seed parents by taking appropriate steps to prevent contamination with foreign pollen, (iv) development of restorer parents through identification of promising restorers, genetic improvement of existing restorers and transfer of restorer genes into high yielding inbred lines and $(v)$ hybrid seed production keeping in view the four key elements - isolation distance, off type removal, flowering synchrony between Aand $\mathrm{R}$-lines, and $\mathrm{A}: \mathrm{R}$ lines ratio are discussed.
\end{abstract}

\footnotetext{
${ }^{1}$ Intemational Crops Research Inst. for the Semi-Arid Tropics, Patancheru 502 324, India

${ }^{2}$ Directorate of Rice Research, Hyderabad 500 030, India

${ }^{3}$ Hybrid Rice Intemational Ltd., Hyderabad 500 008, India
} 


\section{Introduction}

Heterosis for grain and biomass yield has been observed in all crops regardless of their breeding systems. In a highly cross-pollinated crop such as pearl millet [Pennisetum glaucum (L.) R. Br.] (85\% outcrossing), better-parent heterosis of up to $424 \%$ has been reported for grain yield of single-cross hybrids (Virk, 1988). Such a high degree of heterosis for grain yield in pearl millet is a consequence of high degree of inbreeding depression (Rai et al., 1985). Hybrids as a cultivar option are determined more by their yield advantage over improved varieties than by yield advantage over their inbred parents. It has been observed that highest yielding single-cross hybrids of pearl millet have 20-30 $\%$ 'grain yield advantage over the highest yielding open-pollinated varieties of comparable maturity. In predominantly self-pollinated crops such as pigeonpea, Cajanus cajan (L.) Millsp. (15-30\% outcrossing) and sorghum, Sorghum bicolor (L.) Moench, the natural cultivars are homozygous. In cultivated sorghum, depending on cultivars and climatic conditions (particularly wind), the outcrossing ranges from 2 to $15 \%$ (House, 1985). In wild sorghum, it is higher than in the cultivated sorghum (Reddy, 1997). In pigeonpea, the heterosis in hybrids has been reported to be $20-100 \%$ over the best parent of similar maturity (Saxena, 2001a) while in sorghum, it is 15-48 \% (Maunder, 1972). Asian cultivated rice (Oryza sativa L.) is strictly self pollinated (highly autogamous). Natural outcrossing is extremely low (1\%). Depending on environmental conditions and cultivars, the extent of outcrossing may vary from 0 to $6.8 \%$ (Sahadevan and Namboodri, 1963). Through natural cross-pollination, percentage of florets setting seed vary between 0 to 44 $\%$ (Athwal and Virmani, 1972; Carnhan et al., 1972). Commercial rice hybrids are reported to show 20-30 \% standard heterosis for grain yield (Lin and Yuan, 1980; Yuan et al., 1989). The yield advantage in hybrids as percent over high yielding variety has been reported to be $32 \%$ (Virmani, 1996). This order of yield advantage in hybrids is of considerable economic significance, providing the basis for enhanced hybrid research and development efforts.

Hybrid cultivar development requires additional research investment over those needed for non-hybrid cultivars for developing suitable parental lines. The advantage with hybrid technology, however, is that relatively greater number of players find it attractive to invest in it. This is particularly true of private sector, which has been emerging as an important partner in hybrid research and development. Besides the yield advantage, there are several other factors that determine the success of hybrid programs in any crop. The foremost of these is the identification and development of a biological system that helps in economic production of hybrid seed on a commercial scale. Systems such as genetic male sterility in sorghum and pigeonpea, and temperature-sensitive genetic male sterility (TGMS) in rice, have been developed, but at present these do not provide either the economy of scales or the flexibility of choice of locations and seasons during the hybrid seed production in tropical countries. Cytoplasmic-nuclear male sterility (CMS) provides a system that potentially overcomes the above problems, leading to a more reliable and economical 
hybrid seed production technology. CMS systems and hybrid seed production technologies in crops like maize (Zea mays L.), pearl millet and sorghum were developed in early 1960s and became a matter of routine commercial application. Development of such technologies in other crops such as rice (Lin and Yuan, 1980) and pigeonpea (Saxena, 2001a), is a relatively recent effort. The objective of this paper is to review the CMS research relevant to the development of high yielding hybrids in pearl millet, sorghum, rice and pigeonpea.

\section{Origin}

CMS is a physiological abnormality, resulting from a disharmonious interaction between the cytoplasmic factors (now widely identified as mitochondrial genetic factors) and nuclear genetic factors, leading to the production of degenerated or non-viable pollen grains or non-dehiscent anthers with or without functional pollen grains. Understandably, this disharmonious interaction is likely to be more pronounced in populations incorporating divergent sources of cytoplasm and nuclear genes. Thus, in natural landrace populations, CMS is likely to occur more in cross-pollinated crops than in self-pollinated crops. Also, biologically speaking, male-sterility is a negative trait, and as such natural selection pressure works against this trait. As a result, it is more likely to be lost in self-pollinated crops than in cross-pollinated ones.

\section{Cultivated Germplasm}

Segregating populations derived from hybridization programs or composites of hybrid origins serve as useful materials to search for CMS sources, regardless of the breeding system of the crop. Several CMS sources in maize (Duvick, 1965) and the first commercially viable $A_{1}$ CMS sources in both sorghum (Stephens and Holland, 1954) and pearl millet (Burton, 1958) were identif ied in $\mathrm{F}_{2}$ populations derived from crosses between inbred lines of diverse origin. For instance, the $A_{1} C M S$ source in pearl millet was identified in a $F_{2}$ population derived from a cross Tift $556 \times$ Tift 23 . Similarly, the $A_{1}$ CMS source in sorghum was identified in the $F_{2}$ population of cross Double Dwarf Yellow Sooner Milo $\times$ Texas Blackhull Kafir by Stephens and Holland (1954), where the milo inbred belongs to durra race from Sudan and Ethiopia border (Duncan et al., 1991) and the Kafir inbred from Eastern Africa (House, 1985).

A partial listing of 54 CMS sources in maize (Duvick, 1965) showed them having occurred in a wide range of cultivated maize germplasm, mostly open-pollinated varieties. The first two discoveries of CMS sources (Peruvian and Argentinian) in 1930s and the once most commercially used source (Texas $A \& M$ ) in maize were all derived from open-pollinated varieties. Five sources out of 32 tested (4 USA + 1 Mexico) by Duvick (1965) resembled the Texas CMS source, and the remainder the USDA - iojap source. They could not distinguish the two other sources tested. A similar search in pearl millet led to the identification of various CMS sources, which is not unexpected as pearl millet is also an outbreeder (similar to maize) and it is endowed with as much variability, both 
within and between populations, especially in the western African region. Madhava Menon (1959) identified a CMS source in an open-pollinated landrace variety (PT 819) from Bellary district of the then Mysore state. Athwal (1961) identified a CMS source (later designated as $\mathrm{A}_{2}$ ) in IP 189, a landrace population from western Africa. Later, several CMS sources were identified in germplasm collections from Ghana and Botswana (Appa Rao et al., 1989) and in broad-based genepools (Rai and Hash, 1993; Rai, 1995). This shows that open-pollinated varieties and broad-based genepools in cross-pollinated crops provide promising materials, where search for CMS sources could be made. In sorghum, a predominantly self-fertilizing crop, Schertz and Pring (1982) listed more than 40 CMS sources - all from cultivated sources. Nagur and Menon (1974) studied several of these sources and recognized four different classes based on fertility/sterility response in hybrids. These were further studied by Reddy (1992) in an effort to classify them and to find minimum differential testers. These were designated as $\mathrm{A}_{1}$ (CK 60; origin East Africa), $A_{2}$ (IS 12662C; origin Ethiopia), $A_{3}$ (IS 1112C; origin India) and $A_{4}$ (M35-1, VZM 2 and $\mathrm{G} 1$; origin India). Those in the $\mathrm{A}_{4} \mathrm{CMS}$ system were further classified, based on RFLP analysis, into three separate cytoplasms (Sivaramakrishnan et al., 1997). Further, a male-sterile plant was discovered by Webster and Singh (1964) in 9E, a selection made in Ghana. Schertz and Pring (1982) described several analogues of these cytoplasms in sorghum. In pigeonpea, a predominantly self-fertilizing crop as sorghum, no CMS source has yet been reported in the cultivated or landrace varieties. In rice, the role of cytoplasm causing male sterility was first reported by Sampath and Mohanty (1954). The first cytoplasmic male-sterile line used to develop commercial $F_{1}$ rice hybrids was developed in China in 1973 from a male-sterile plant in a population of wild rice - Oryza sativaf. spontanea (Yuan, 1977). The sterile plant designated as wild rice with abortive pollen (WA) served as source for a number of CMS lines (Lin and Yuan, 1980; Virmani et al., 1986). Later on, indica $\times$ japonica crosses of the cultivated rice yielded several new CMS sources in China. Lin and Ming (1991) (C.f. Virmani, 1996) described four such new sources: Seng Qi, Nan Guang Zhan, Gui Hua Huang and Zhao Tong Beizigu. Other CMS sources identified are: V20B, Kalinga-1, Ptb 10, Co 41 (Pradhan et al., 1990) and Lalruma (Pradhan and Jachuck, 1998). Among them V20B maintains CMS-WA (wild source), but it itself is a japonica cultivar. In Japan, CMS system in rice was reported by Shinjyo and Omura (1966) and Shinjyo (1969) in indica var. Chinsurah Boro II, which had S cytoplasm and R gene and variety T-65 having a maintainer gene. This cytoplasm was named as BT or BO. Similarly, Athwal and Virmani (1972) identified the variety TN 1, which had both CMS cytoplasm and R gene, whereas variety Pankhari 203 was found to be a maintainer of sterility. No stable CMS lines from this could, however, be established. Li Zhengyon (1980) identif ied CMS plants in variety Teibei 8 and later developed a japonica male-sterile line of Dien 1 type. Several other CMS sources identif ied in rice are given in Table 1. 
Table 1. CMS sources in cultivated and wild germplasm of sorghum, pearl millet, rice, and pigeonpea.

\begin{tabular}{|c|c|c|}
\hline Germplasm type & Crop & CMS sources \\
\hline \multirow[t]{4}{*}{ Cultivated } & Sorghum & $\begin{array}{l}A_{1}, A_{2}, A_{3}, A_{4}\left(G_{1}, \text { Maldandi and VZM }\right) \text { and } 9 E \text { and several } \\
\text { analogues }\end{array}$ \\
\hline & Pearl millet & $\begin{array}{l}A_{1}, A_{2}, A_{3}, A_{5}, \text { Aegp, PT } 732 \text {, DSA 59-1A, DSA 105A, DSA } \\
118 A \text {, DSA } 134 \text { A, DSA 1444-1A, PMC 23A, PMC, 30A }\end{array}$ \\
\hline & Rice & $\begin{array}{l}\text { Chinsurah Boro II, Lead rice, Tadukan, Tian Dong, Dong Pu, } \\
\text { TN 1, Gambiaca, Birco, Tian Ji Du, IR 24, Jing Chuan Nao, } \\
\text { Sheng Qi, Li Up, Zhao Jin Feng, Zhao Tong Bei, Dissi Hatif, } \\
\text { V20B, Kalinga-I, Lalruma, Khiaboro }\end{array}$ \\
\hline & Pigeonpea & Nil \\
\hline \multirow[t]{4}{*}{ Wild } & Sorghum & Nil \\
\hline & Pearl millet & $\mathrm{Av}, \mathrm{A}_{4}$ \\
\hline & Rice & $\begin{array}{l}\text { Oryza sativa } f . \text { spontanea (WA), Red-awned wild, O. sativa } f \text {. } \\
\text { spontanea (Dwarf WA), ARC } 13829-16, \text { O. perennis, } \\
\text { O. glumaepatula, } \\
\text { O. rufipogon, } O \text {. nivara }\end{array}$ \\
\hline & Pigeonpea & Cajanus sericeus and C. scarabaeoides \\
\hline
\end{tabular}

\section{Wild Germplasm}

Based on the premise that cytoplasm $\times$ nuclear interactions are likely to be more disharmonious in crosses involving divergent materials, the probability of identifying CMS will be more in populations derived from wild $\times$ cultivated crosses than in those derived from cultivated $\times$ cultivated crosses, as the former offers far greater diversity. In such crosses, it is important that the wild germplasm is used as female parent, as it is likely to have a higher frequency of the wild alleles (i.e. dominant restorers) than mutant alleles (i.e., recessive maintainers). Two CMS sources (designated as Av and $\mathrm{A}_{4}$ ) in pearl millet were identified in the $\mathrm{F}_{2}$ populations derived from crosses between germplasm accessions of $P$. glaucum ssp. monodii (= violaceum) (used as female parents) and cultivated pearl millet germplasm used as male parents (Marchais and Pernes 1985; Hanna, 1989). Several other CMS sources recently identified from monodii $\times$ cultivated crosses, are being evaluated for their cytoplasmic diversity (W.W. Hanna, personal communication). Stable CMS sources in sorghum have not been identified for use in hybrid program so far from the wild germplasm. In pigeonpea, CMS lines have been derived from inter-specific crosses involving cultivated types as male and its wild relatives as female parents. At ICRISAT, $C$. sericeus and at Gujarat Agricultural University, C. scarabaeoides were used as cytoplasm donors (Saxena, 2001a). In rice, the real breakthrough in developing commercial $F_{1}$ hybrid rice came when a natural male-sterile plant was found in wild rice $O$. sativa f. spontanea in China. This CMS source, as indicated earlier, is designated as CMS-WA. More than 20 cytoplasms of wild rice have been identif fed and several CMS lines were derived by using distant nucleus substitution backcrosses. The CMS lines have also been developed involving 
inter-specific crosses using wild rice (O. perennis, O. glaberrima or $O$. rufipogon) as female parent, and cultivated rice like $O$. sativa as male parents. In 1973, Sichuan Agriculture College reported development of CMS line using Gambiaca (an indica variety of West Africa) as source of cytoplasm. In 1977, Wuhan University reported development of indica CMS line of Honglien type in which sterile cytoplasm was from red-awned wild rice. Pradhan et al. (1990) identified two new CMS sources, V20B and sattari, through indica $\times$ japonica hybridization. Recently, two CMS lines viz., IR 66707A with cytoplasm from $O$. perennis and nuclear genome of IR 64; and IR 69700A with cytoplasm of $O$. glumaepatula and nuclear genome of IR 64 have been developed. Genetic tests show that these lines possess cytoplasm that are different from WA cytoplasm (Dalmacio et al., 1995; 1996). Recently, new CMS lines viz., RPMS 1 (O. rufipogon), RPMS 2 (O. nivara) and RPMS 4 (O. rufipogon) have been developed at the Directorate of Rice Research (Hoan et al., 1997). There are other systems such as thermosensitive genetic male sterility (Maruyama et al., 1991), but these are outside the scope of this review.

Further details of various CMS systems that have potential use in hybrid development are given in Table 2 .

Table 2. Potential CMS systems for commercial utilization in sorghum, pearl millet, rice, and pigeonpea

\begin{tabular}{llll}
\hline Crop & CMS system & Origin & Reference \\
\hline Sorghum & $\mathrm{A}_{1}$ & Milo (CK 60A) $\mathrm{A}_{1}$ & Stephens and Holland (1954) \\
& $\mathrm{A}_{2}$ & Caudatum-Nigricans (IS 12662C) & Schertz and Ritchey (1977) \\
Pearl millet & $\mathrm{A}_{1}$ & Tift 556 & Burton (1958) \\
& $\mathrm{A}_{4}$ & P. glaucum subsp. monodii & Hanna (1989) \\
& $\mathrm{A}_{5}$ & Large-seeded genepool & Rai (1995) \\
Rice (Indica) & WA-CMS & O. sativa f. spontanea & Lin and Yuan (1980) \\
& Gam & Gambiaca & Lin and Yuan (1980) \\
& Dwarf WA & Dwarf MS wild rice & Virmani and Wan (1988) \\
Pigeonpea & & C. sericeus and C. scarabaeoides & Saxena (2001a) \\
\hline
\end{tabular}

\section{Evaluation}

Although numerous CMS sources have been found in the crops under discussion, all have not been found commercially useful. There are various factors that determine the utility of a CMS system. These include stability of male sterility, effect of genetic background on male sterility, maintainer gene frequency in germplasm, character association, and male fertility restoration behaviour.

\section{Stability of Male Sterility}

Instability of male sterility in A-lines increases the problem of roguing of pollen shedders from seed production plots (i.e., higher seed production cost). Further, hybrid seed yields are also reduced. Such an unstable CMS system also reduces breeding efficiency as the backcross progenies found fully sterile initially may not be necessarily so during the subsequent generations, leading to their rejection. Stability of male sterility also has a 
direct bearing on the cost and quality of hybrid seed production. Ideally, a commercial male sterile line should neither shed pollen nor should it set seed when selfed, regardless of the location and the season. This, however, is seldom possible. For instance, several A-lines based on the $\mathrm{A}_{1} \mathrm{CMS}$ systems in both sorghum and pearl millet, have been extensively used to breed hybrids, which are planted on millions of hectares in India alone. Yet, most of these A-lines produce, albeit low frequency $(<1 \%)$ of pollen shedders, depending on the environment. In maize, cooler weather promotes instability in male sterility in both USDA and Texas CMS sources, and hot dry weather promotes stability of male-sterility (Duvick, 1965).

In pearl millet, it has been observed that $\mathrm{A}_{1} \mathrm{CMS}$ lines produce a relatively higher frequency of pollen shedders during the rainy season than in the dry season. Three new CMS systems ( $\mathrm{A}_{4}, \mathrm{~A}_{5}$ and Aegp) have been identified in recent years in pearl millet which produce A-lines with no or much less pollen shedders. In case of sorghum, several workers reported the role of temperature on the expression of male sterility and fertility restoration (Downes and Marshall, 1971; Li et al., 1981). It affects some cytoplasms more th an the others (Schertz et al., 1997). The work at ICRISAT showed that fertility restoration is poor when night temperature falls below $10^{\circ} \mathrm{C}$ just before flowering, during post rainy season, and that the male sterility in CMS lines breaks down when-the day temperature rises above $42^{\circ} \mathrm{C}$, before flowering (Reddy and Stenhouse, 1994). This evidently increases the need to screen the CMS lines in areas where the temperature rises above $42{ }^{\circ} \mathrm{C}$ before flowering for the absence of seed setting under bag to ensure stability of male sterility. The hybrids need to be screened in areas where night temperatures are low for seed setting under bags to identify stable fertility restorers. We compared $A_{1}, A_{2}$, $A_{3}$ and $A_{4}$ male-sterile lines for seed setting under selfing during summer (when temperatures exceed $42{ }^{\circ} \mathrm{C}$ ) at Bhavanisagar, India. It was found that the $\mathrm{A}_{1}$ is more stable in maintaining male sterility than $A_{2}, A_{3}$, and $A_{4}$ (Maldandi); $A_{3}$ is more stable than $A_{2}$ and $A_{4}$; and $A_{2}$ is more stable than $A_{4}$ (Reddy and Stenhouse 1994). Devi and Murthy (1993) showed that the tapetum was intact and pollen was sterile in $A_{2}$ male-sterile lines in winter (low temperature), while partial or complete-degeneration of tapetum occurred and viable pollen grains were found in summer (high temperature), indicating the unstable nature of male sterility in $\mathrm{A}_{2} \mathrm{CMS}$ system. At ICRISAT, the low temperature-induced female sterility in $\mathrm{A}_{1}$ CMS female lines (e.g. 296A) indicated that female sterility may be reduced significantly by using their non-parental single cross $\mathrm{F}_{1}$ male-sterile lines (Reddy, 1992). At ICRISAT, in maintainer lines development programme, the frequency of maintainer lines observed in $A_{1}$ (Table 3) and $A_{2}$ CMS systems (Table 4) was higher in post-rainy season (cooler temperature) than in the rainy season (warmer temperature). Others in Indian National programs reported that fertility restoration frequency in $\mathrm{A}_{2}$ CMS system is higher in post-rainy season than in rainy season (U. R. Murthy, personal communication). However, the data presented in Table 4 do not support the above observation. Further data are required involving same females in both seasons. 
Table 3. Maintainer and restorer frequencies in sorghum $A_{1}$ cytoplasm in rainy and postrainy seasons at ICRISAT, Patancheru

\begin{tabular}{llccc}
\hline Season & A line & Total testcrosses & \multicolumn{2}{c}{ Frequency } \\
& & & Maintainers & Restorers \\
\hline Rainy season 2000 & ICSA 56 & 75 & 0.80 & 0.20 \\
& ICSA 84 & 66 & 0.82 & 0.18 \\
& ICSA 101 & 95 & 0.84 & 0.16 \\
& CK 60 A & 49 & 0.86 & 0.14 \\
Post-rainy season 2000 & Total & $\mathbf{2 8 5}$ & $\mathbf{0 . 8 3}$ & $\mathbf{0 . 1 7}$ \\
& ICSA 1 & 39 & 0.62 & 0.38 \\
& ICSA 9 & 39 & 0.87 & 0.13 \\
& ICSA 101 & 200 & 0.95 & 0.06 \\
& ICSA 88005 & 21 & 0.90 & 0.10 \\
& Total & $\mathbf{2 9 9}$ & $\mathbf{0 . 8 9}$ & $\mathbf{0 . 1 1}$ \\
\hline
\end{tabular}

Table 4. Maintainer and restorer frequencies in sorghum $A_{2}$ cytoplasm in rainy and postrainy seasons at ICRISAT, Patancheru.

\begin{tabular}{llccc}
\hline Season & A line & Total test-crosses & \multicolumn{2}{c}{ Frequency } \\
& & & Maintainers & Restorers \\
\hline Rainy season 1999 & MR 750 & 215 & 0.84 & 0.16 \\
& ICSA 94003 & 55 & 0.95 & 0.05 \\
& Total & $\mathbf{2 7 0}$ & $\mathbf{0 . 8 6}$ & $\mathbf{0 . 1 4}$ \\
Post-rainy season 1999 & MR 750 & 19 & 0.84 & 0.16 \\
& ICSA 88004 & 110 & 0.86 & 0.14 \\
& ICSA 94001 & 20 & 0.85 & 0.15 \\
Post-rainy season 2000 & ICSA 38 & 133 & 0.97 & 0.03 \\
& ICSA 743 & 72 & 1.00 & 0.00 \\
& ICSA 88001 & 34 & 0.85 & 0.15 \\
& Total & $\mathbf{3 8 8}$ & $\mathbf{0 . 9 2}$ & $\mathbf{0 . 0 8}$ \\
\hline
\end{tabular}

In pigeonpea, breakdown of male sterility is common at low temperatures and short photoperiod, as observed in some CMS lines at ICRISAT, (Saxena, 2001b). In pearl millet, breakdown in male sterility occurs in rainy season due to high humidity. Unlike in cross-pollinated crops, absolutely complete stability of male sterility is of high signif icance in self-pollinated crops like rice. Initially, in hybrid rice program, a male sterile line, viz. IR 58025A (WA cytoplasm) was used in developing hybrids. This line, on account of its instability for male sterility, always resulted into some female type sterile plants in $\mathrm{F}_{1}$ hybrids. A similar difficulty was encountered with another CMS line IR 62829A (WA cytoplasm). However, now both these lines are in use. Most commonly used female line now is IR 58025A (WA cytoplasm). The previously suspected instability in male-sterility in female line IR 58025A does not hold true any more, as many completely 
genetically homogeneous pure hybrids have been commercialized with this line. Thus, any pollen shedders observed by some breeders in this line could be attributed to contamination resulting from incomplete isolation during the maintenance of this line, and not due to instability of the line. Various newly developed WA-CMS lines have shown complete male sterility under different climatic conditions, and are perfectly usable for development of new hybrids.

\section{Effect of Genetic Background on Male Sterility}

Nuclear genetic diversity of A-lines provides opportunity for diversifying the genetic base of hybrid cultivars with higher yield potential. The effectiveness of such genetic diversification efforts is determined by whether or not the genetic background of maintainer lines (B-lines) influences the stability of male sterility of A-lines produced from them. In case of the $A_{1}$ CMS system in pearl millet, it has been observed that a good maintainer of an A-line is not necessarily a good maintainer of another unrelated A-line carrying the same cytoplasm (Table 5), indicating the effect of nuclear genetic background of B-lines on male sterility. In sorghum, the kafir-based crosses with $\mathrm{CK} 60 \mathrm{~B}$ produce higher frequency of B-lines than the caudatum-based B-lines with $\mathrm{A}_{1} \mathrm{CMS}$ source, which essentially derives its male-sterility maintainer genes from kafir.

Table 5. Average pollen shedding scores of male sterile $\times$ maintainer pearl millet hybrids for two seasons in $2 \mathrm{yr}$ at ICRISAT Center.

\begin{tabular}{|c|c|c|c|c|c|c|c|c|c|c|c|c|c|c|c|c|c|c|c|c|}
\hline \multicolumn{21}{|c|}{ B-lines } \\
\hline & \multicolumn{4}{|c|}{$5141 \mathrm{~B}$} & \multicolumn{4}{|c|}{$\mathrm{Pb} 111 \mathrm{~B}$} & \multicolumn{5}{|c|}{$81 \mathrm{~B}$} & \multicolumn{3}{|c|}{$842 \mathrm{~B}$} & \multicolumn{4}{|c|}{$843 \mathrm{~B}$} \\
\hline \multicolumn{21}{|c|}{ Average pollen shedding scores } \\
\hline A-line & $\mathrm{A} \dagger$ & $\mathrm{B}$ & $\mathrm{C}$ & $\mathrm{D}$ & A & $\mathrm{B}$ & $\mathrm{C}$ & $\mathrm{D}$ & A & $\mathrm{B}$ & $\mathrm{C}$ & $\mathrm{D}$ & A & $\mathrm{B}$ & $\mathrm{C}$ & $\mathrm{D}$ & A & $\mathrm{B}$ & $\mathrm{C}$ & $\mathrm{D}$ \\
\hline $5141 \mathrm{~A}$ & $1 \ddagger$ & 1 & 1 & 1 & 4 & 4 & 4 & 4 & 1 & 1 & 1 & 1 & 4 & 4 & 4 & 4 & 3 & 3 & 4 & 3 \\
\hline $\mathrm{Pb} 111 \mathrm{~A}$ & 3 & 3 & 4 & 4 & 1 & 1 & 1 & 1 & 1 & 1 & 1 & 1 & 4 & 4 & 4 & 4 & 4 & 4 & 4 & 4 \\
\hline $81 \mathrm{~A}$ & 1 & 1 & 1 & 1 & 1 & 1 & 1 & 1 & 1 & 1 & 1 & 1 & 1 & 1 & 1 & 1 & 1 & 2 & 1 & 1 \\
\hline $842 \mathrm{~A}$ & 3 & 4 & 4 & 4 & 4 & 3 & 4 & 1 & 1 & 1 & 1 & 1 & 1 & 1 & 1 & 1 & 4 & 4 & 4 & 4 \\
\hline $843 \mathrm{~A}$ & $\$$ & - & - & - & 4 & 4 & 4 & 4 & 1 & 1 & 1 & 1 & 2 & 2 & 1 & 1 & 1 & 1 & 1 & 1 \\
\hline $834 \mathrm{~A}$ & 4 & 4 & 4 & 4 & 3 & 4 & 4 & 3 & 3 & 4 & 1 & 1 & 4 & 4 & 3 & 1 & 4 & 4 & 4 & 4 \\
\hline PT 32A & 4 & 4 & 2 & 3 & 4 & 4 & 4 & 4 & 3 & - & 1 & - & 4 & 4 & 4 & 4 & 4 & 4 & 4 & 4 \\
\hline
\end{tabular}

†A-Rainy season 1985; B-Rainy season 1986; C-Dry season 1986; D-Dry season 1987; $\ddagger 1$-All plants having shrunken anthers and shedding no pollen; 2-Most of the plants having shrunken anthers and shedding no pollen; 3-Most of the plants having plump anthers and shedding pollen; 4-All plants having plump anthers and shedding pollen; \$-Not tested; Adopted from Rai and Hash (1993).

At ICRISAT, the maintainer gene frequency ranged from 0.5 to 1.0 in the derivatives of various sets of crosses with $A_{1}$ CMS system (Table 6), although both the parents involved in such crosses were maintainers. 
Table 6. Maintainer and restorer frequencies in various sorghum $A_{1} C M S$ maintainer lines derived from $\mathrm{B} \times \mathrm{B}$ crosses at ICRISAT, Patancheru

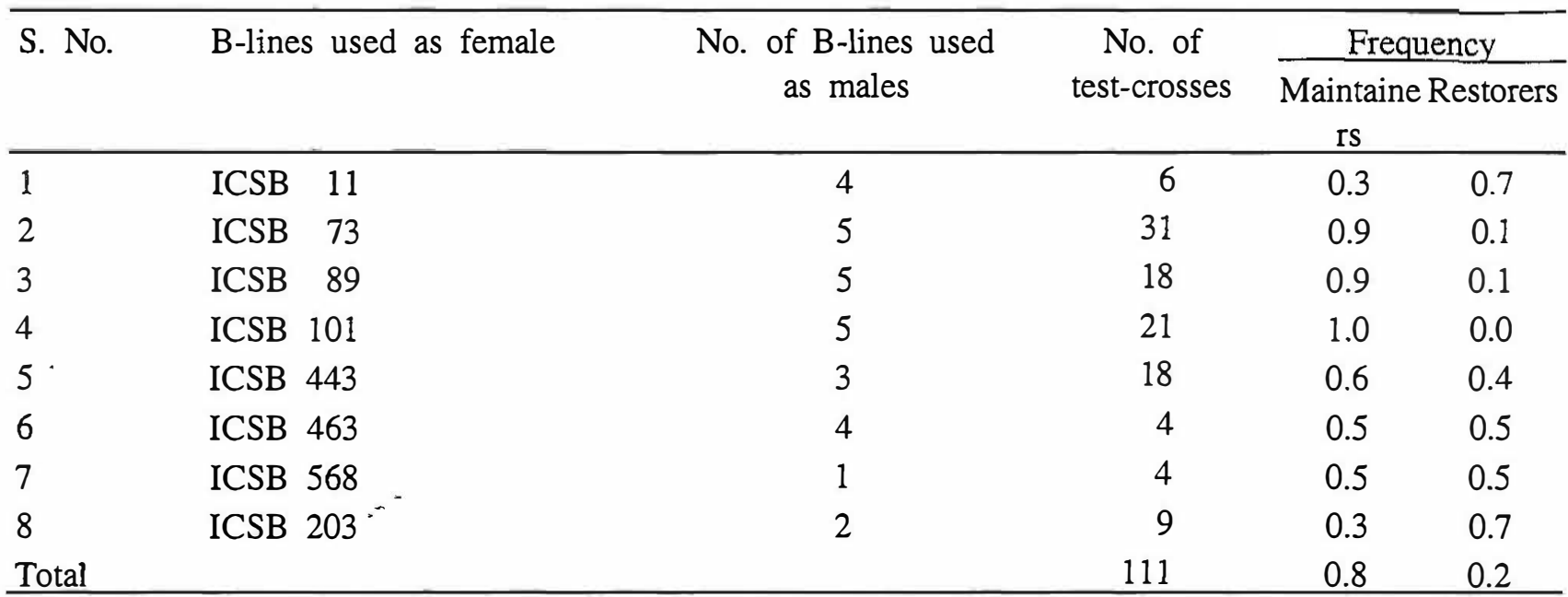

In rice, the expressivity of fertility restorer $(R)$ gene varies depending on the nuclear background of the female parent, even though they possess the same cytoplasm (Kumari et al., 1998). To cite an example, hybrids involving varieties C 29 and PMK 2 with WA-cytoplasmic male sterile (CMS) lines IR 58025A, IR 62829A and PMS 3A - showed marked differences in pollen and spikelet fertility. C 29 behaved as a partial restorer with IR 62829A and PMS 3A (21-90 \%), but with IR 58025A it behaved as maintainer, though both females belong to the same CMS system. Similar is the effect of PMK 2. This type of variation may be due to presence of modifier genes present in the R parents (Ganesan et al., 1998). Govindraj and Virmani (1988) presented evidence for inhibitory genes present in a CMS line of rice causing incomplete fertility restoration by some established restorer lines. Similarly, CMS lines V20A, IR 58025A, and IR 62829A which have the same cytoplasm but different nuclear genotypes, showed differences in maintainer frequency (Virmani, 1994). In such cases, some of the inbred lines derived from $B \times B$ crosses are likely to be poor maintainers, leading to reduced A-line breeding efficiency. Stability of male fertility is another important factor in rice. It has been observed that some hybrids which show complete spikelet fertility in northern India, show only partial fertility in southern Indian region. Variations in fertility restoration across locations have also been observed within the region. In a typical case (Ish Kumar, unpublished) one hybrid showed complete fertility in Mandya (Kamataka), whereas, it was observed to have lowest fertility (partially sterile) in Hyderabad (Andhra Pradesh) in India. Use of such male parents must be discouraged, as they do not provide widely adapted fertile hybrids.

\section{Maintainer or Restorer Gene Frequency}

Frequency of maintainer gene in a diverse range of improved populations and breeding lines has a direct bearing on the success of genetic diversification of A-lines. Conversely, the frequency of restorers influences directly the use of such diversified male-steriles in grain hybrid development. It has been observed that only 10-15\% of the inbred lines. 
behave as complete and stable maintainers of the $A_{1}$ CMS system in pearl millet, and relatively large proportions behave as partial and unstable maintainers. In contrast, more than $60 \%$ of the inbred lines behave as complete and stable maintainers of the $\mathrm{A}_{4} \mathrm{CMS}$ system and more than $99 \%$ of the inbred lines behave as complete and stable maintainers of the $\mathrm{A}_{5} \mathrm{CMS}$ system. Thus, the $\mathrm{A}_{4}$ and $\mathrm{A}_{5} \mathrm{CMS}$ systems provide much greater opportunities for genetic diversification of A-lines in pearl millet.

The very low frequency of restorers of the $\mathrm{A}_{5} \mathrm{CMS}$ system in pearl millet poses problems in its utilization for grain hybrid program, Therefore, based on the premise that the same germplasm source where the $\mathrm{A}_{5} \mathrm{CMS}$ was identified should also be a source of its restorers, an extensive search was conducted in the Large-seeded genepool 1 (the source of $\mathrm{A}_{5}$ cytoplasm), four other diverse and broad-based genepools and two open-pollinated varieties. Low frequency of restorers were identified in each population (Table 7), although large variations occurred in the level of fertility restoration ability across the populations. A highly male fertile restorer stock in the $\mathrm{A}_{5}$ cytoplasmic background was developed from a fertile plant in the hybrid made with the Large-seeded genepool 1, which produces prof use pollen and gives more than $90 \%$ seed set under selfing, both per se as well as in the hybrid made on $81 \mathrm{~A}_{5}$. In general, finding commercially viable restorers is much less of a problem than finding maintainers in cross-pollinated crops. This is because, even a lower level of fertility restoration in hybrids of cross-pollinated crops may have no adverse effect on grain yield. In fact, reduced male fertility level in hybrids appears to be associated with higher grain yield in maize (Duvick, 1965) and pearl millet (KN Rai, unpublished). Thus, stability of male fertility is more important than the lower level of stable male fertility. For instance, the otherwise male fertile pearl millet $\mathrm{A}_{1}$-system hybrids in the midwest of the United States have been found to turn sterile in the event of temperatures falling below $10^{\circ} \mathrm{C}$ during flowering. Temperature sensitivity of fertility restoration in other CMS systems of pearl millet is yet to be investigated.

Table 7. Pollen-fertile plants in topcross hybrids of four pearl millet genepools and two open-pollinated varieties of OPVs crossed onto $81 \mathrm{~A}_{5}$, Patancheru.

\begin{tabular}{|c|c|c|c|c|}
\hline \multirow[t]{2}{*}{ Genepool/OPV } & \multirow[t]{2}{*}{ Season } & \multirow{2}{*}{$\begin{array}{l}\text { No. of hybrid } \\
\text { plants }\end{array}$} & \multicolumn{2}{|c|}{ Pollen-fertile hybrid plants } \\
\hline & & & Number & Per cent \\
\hline Genepool & 1995 rainy & & & \\
\hline Early & & 694 & 9 & 1.3 \\
\hline Large-seeded (LSGP 1) & & 645 & 6 & 0.9 \\
\hline Large-seeded (LSGP 2) & & 723 & 1 & $<0.1$ \\
\hline Large spike & & 661 & 9 & 1.4 \\
\hline High tillering & & 721 & 11 & 1.5 \\
\hline OPV & 1997 rainy & & & \\
\hline ICMR 312 & & 541 & 76 & $14.0^{1}$ \\
\hline IAC-ISC TCP 2 & & 544 & 42 & $0.7^{2}$ \\
\hline
\end{tabular}

1. Includes 61 plants $(80.3 \%$ of the pollen-fertile plants) that had poor pollen shed; 2 . All plants had poor pollen shed; Source: Rai et al. (1999) 
In sorghum, Scheuring and Miller (1978) found a restorer frequency of 0.62 and maintainer frequency of 0.23 on milo $\left(A_{1}\right)$ cytoplasm in the world collection of 3,507 sorghum accessions. The work carried out at ICRISAT showed a restoration frequency of 0.9 on $A_{1}, 0.5$ on $A_{2}, 0.1$ on $A_{3}$, and 0.3 on $A_{4}$, when 48 germplasm lines were test-crossed onto $A_{1}, A_{2}, A_{3}$, and $A_{4} C M S$ systems (Belum Reddy, unpublished data). Senthil et al. (1998) found that the frequency of restorers was 0.15 on $A_{1}, 0.04$ on $A_{2}$, 0.01 on $A_{3}$, and 0.03 on $A_{4} C M S$ systems. This suggests that the restorer frequency is high on $A_{1}$ and low on $A_{3}$ system. Considering the restoration frequency, $A_{1}$ CMS system provides the widest possible choice in selecting restorers. In $\mathrm{B}$-line development programme, the restorer gene frequency is also higher in $A_{1} C M S$ system than in $A_{2}, A_{3}$, and $\mathrm{A}_{4}$ (Table 8).

Table 8. Maintainer and restorer frequency in various cytoplasms of sorghum in rainy and post-rainy seasons, 1999 and 2000 at ICRISAT, Patancheru

\begin{tabular}{lccccc}
\hline Season & Cytoplasm & $\begin{array}{c}\text { A-lines used in } \\
\text { test-crossing }\end{array}$ & $\begin{array}{c}\text { Total no. of } \\
\text { pollinators }\end{array}$ & \multicolumn{2}{c}{ Frequency } \\
& & 4 & 285 & 0.83 & Maintainers \\
\hline Rainy & $\mathrm{A}_{1}$ & 2 & 270 & 0.86 & 0.17 \\
& $\mathrm{~A}_{2}$ & 4 & 299 & 0.89 & 0.11 \\
Postrainy & $\mathrm{A}_{1}$ & 6 & 388 & 0.92 & 0.08 \\
& $\mathrm{~A}_{2}$ & 4 & 94 & 0.86 & 0.14 \\
Variable & $\mathrm{A}_{3}$ & 4 & 82 & 0.84 & 0.16 \\
Variable & $\mathrm{A}_{4}$ & 4 & \\
\hline
\end{tabular}

In case of completely self-pollinated crops like rice, high level of fertility restoration is very important. Low level of fertility restoration in rice has been found to give hybrids with partial sterility, which is due to lack of out-pollination. The commercial acceptability of such hybrids in the market is very low, as the lower fertility reduces the heterotic effect for grain yield. Studies carried out at the International Rice Research Institute (IRRI), Philippines showed that the frequency of maintainer lines was higher in elite lines from Korea (japonica rice) than those from India, Pakistan, Philippines, Indonesia and Vietnam. It is generally observed that effective restorers were concentrated in races cultivated in south and south-east Asia, and southern China while non-restorers were concentrated in northern China and far-eastern Asia. Frequency of restorer lines in rice has been reported to be generally higher in varieties of geographic origin from lower latitudes compared to those from higher latitudes. Furthermore, restorer frequency is higher in indica races (18\%) compared to japonica. In China, long duration indica. races showed higher frequency of restorers than the early maturing indica races (Yuan, 1985). Such a correlation may not hold good outside China, because of extensive hybridization between late and early rice cultivars (Yuan and Virmani, 1988). However, in Indian subcontinent, aman, Assam and boro races of indica showed high frequency of restorers (Lin and Zhu, 1988). The frequency of restorer gene in breeding material varied from 9 to $33 \%$ at different centers in India (Anonymous, 1998).

In pigeonpea, male fertility restorer frequency is very low. Only two varieties, HPL 24 and ICPL 129-3 have been found to restore the fertility of CMS lines based on C. sericeus cytoplasm (Saxena, 2001b). 


\section{Effects of Male Sterility Inducing Cytoplasm}

Commercial viability of a CMS system depends on the extent of its association with characters of economic importance. The once most widely used Texas CMS source in maize is a historical example, which had to be withdrawn from field deployment because of its association with southern leaf blight caused by Bipolaris maydis (Nisikado) Shoemaker (Scheifele et al., 1970). A downy mildew (Sclerospora graminicola (Sacc.) Schroet) epidemic on a pearl millet hybrid HB-3 (developed on male-sterile line, Tift 23 $A_{1}$ ) that occurred in India during 1971 , gave an initial suspicion that the $A_{1}$ cytoplasm was associated with this disease. Later studies showed that the $A_{1}$ cytoplasm in pearl millet had nothing to do with the susceptibility to downy mildew (Anand Kumar et al., 1983; Yadav et al., 1993). Although pearl millet hybrids based on the $\mathrm{A}_{1}$ cytoplasm are more susceptible than open-pollinated varieties to both ergot (Claviceps fusiformis Loveless) and smut (Tolyposporium penicillariae Bref), it has been found to be due to the CMS-mediated reduced male fertility rather than due to the cytoplasm per se (Rai and Thakur, 1995; 1996). Similarly, A-lines and their hybrids have been found to give signif icantly higher grain yield than their counterpart B-lines and hybrids, but this also appears to be associated with CMS-induced male sterility rather than due to the effect of cytoplasm per se (KN Rai, unpublished). The $\mathrm{A}_{1}$ cytoplasm has been observed to cause a day or two of earliness, but this difference is of no practical significance.

In sorghum, Sharma et al. (1994) found that spikelet damage and adult emergence of midge was significantly lower on midge resistant B-lines (PM 7061 and PM 7068) of $\mathrm{A}_{1}$ CMS source than their corresponding $A$-lines and vice versa in the midge susceptible-parental lines (296A/B and ICSA/B 42). At ICRISAT, considerable variation was observed between male-sterile lines and maintainer lines in $A_{1}$ CMS system for flowering. In early group, a few A-lines tend to be late by a day or two, which is not of much significance. But in the medium and late maturity groups, A-lines tend to be late in flowering in significant number and there is a tendency of increased delay in A-lines flowering with increased maturity period (Table 9). B-lines have more open panicles than their A-lines.

Table 9. Frequency of sorghum male-sterile and maintainer lines differing in days to $50 \%$ flowering at ICRISAT, Patancheru

\begin{tabular}{cccc}
\hline Differences in days (A-B) & \multicolumn{3}{c}{ Frequency of A/B lines in maturity groups } \\
\cline { 2 - 4 } & Early $(<67$ days $)$ & Medium $(67-74$ days $)$ & Late $(>74$ days $)$ \\
\hline-2 & 0.00 & 0.02 & 0.04 \\
-1 & 0.00 & 0.08 & 0.08 \\
0 & 0.74 & 0.41 & 0.31 \\
1 & 0.24 & 0.40 & 0.35 \\
2 & 0.03 & 0.09 & 0.19 \\
3 & 0.00 & 0.00 & 0.04 \\
Total number tested & 34 & 108 & 26 \\
\hline
\end{tabular}


Further, $A_{1}$ cytoplasm is more susceptible to shoot fly than the maintainer line cytoplasm, while the reverse is true for stem borer resistance (Belum Reddy, unpublished data). This finding has significance in developing shoot fly resistant hybrids.

In rice, CMS has been observed to affect panicle exertion. The panicle exertion of CMS lines is not complete, when compared to the B-line with normal cytoplasm. The hybrid, however, does not face incomplete exertion, as the negative effect of male sterility inducing cytoplasms is rectified due to restoration of fertility and heterosis for peduncle length. The hybrids, thus, have complete panicle exertion. Yang (1980), Pan (1982) and Shen (1982) found cytoplasmic effects on grain weight, but through right combinations, the cytoplasmic effects could be overcome in the hybrids of parents with high combining ability and high fertility restoration ability. Another effect of WA cytoplasm is that it delays flowering by 4-6 days compared to its counterpart B-line cytoplasm. This difficulty can, however, be overcome by staggered sowing of A- and B-lines. So far, CMS cytoplasms have not been found to be associated with susceptibility to any major diseases or insects in rice.

\section{CMS Diversity}

The need for cytoplasmic diversification of A-lines (and hybrids) to reduce the potential risk of disease and insect pest epidemics associated with cytoplasmic uniformity is a common knowledge. What has not generally been appreciated is that cytoplasmic diversification also enhances the ability of a plant breeder to diversify the genetic base of A-lines, as some of the outstanding inbred lines not found to be maintainers of one CMS system may be maintainers of the other CMS systems.

There are two approaches of CMS diversity analysis which serve two different but overlapping purposes. The first one deals with the traditional field evaluation of hybrids for differential patterns of male fertility restoration, while the second one deals with the mitochondrial DNA (mtDNA) analysis. The differential fertility restoration patterns of hybrids provides an evidence that the CMS sources involved in the study are different from each other, both for nuclear as well as mitochondrial genes. Schertz and Pring (1982) reviewed sorghum CMS and provided a summary of various cytoplasm sources studied through fertility restoration patterns i.e. 42 in India, 24 in USA, and one in Africa. Some of the cytoplasms were reported to be similar in reaction, considering their restoration patterns. For example, Schertz and Pring (1982) (quoting U.R. Murthy, 1996, personal communication) indicated that cytoplasms of G1 (G1-S, ms G1, G1-G, G1-A) are analogous to IS $1112 \mathrm{C}$ of USA. Over the years, many of these cytoplasm sources were either lost and/or not widely available. The most commonly available ones include: $A_{1}$ (milo source), $\mathrm{A}_{2}$ (IS $12662 \mathrm{C}$ or TAM 428), $\mathrm{A}_{3}$ (IS 1112C) and 9E (a selection made in 9E) of USA source, and $\mathrm{A}_{4}$ (Guntur, VZM, and Maldandi) of Indian source. These cytoplasms have been categorized based on the pattern of fertility restoration. Reddy and Stenhouse (1994) reported the identification of minimum differential testers for $A_{1}$ to $A_{4}$ cytoplasms as follows: 
- TAM 428B $\left(\mathrm{A}_{2}\right)$ gives fertile $\mathrm{F}_{1}$ s only on $\mathrm{A}_{1}$ cytoplasm,

- IS 84B ( $\mathrm{A}_{4}$-Maldandi) gives fertile $\mathrm{F}_{1} \mathrm{~s}$ on $\mathrm{A}_{1}$ and $\mathrm{A}_{2}$ cytoplasms,

- IS 5767R $\left(\mathrm{A}_{4}\right.$-Maldandi) gives fertile $\mathrm{F}_{1} \mathrm{~s}$ on all cytoplasms, except $\mathrm{A}_{3}$, and

- CK 60B $\left(\mathrm{A}_{1}\right)$ gives male-sterile $\mathrm{F}_{1}$ s on all cytoplasms

Based on anther morphology and pollen development, these $A_{1}$ to $A_{4}$ (Guntur, VZM, Maldandi) and 9E cytoplasms were further subdivided into two distinct groups: (i) those with small anthers but without fertile pollen, which degenerates during microsporogenesis $\left(\mathrm{A}_{1}\right.$ and $\left.\mathrm{A}_{2}\right)$ and (ii) those with large non-dehiscent anthers that may contain some viable pollen $\left(A_{3}, A_{4}\right.$ and 9E) (Schertz et al., 1989). ICRISAT is maintaining $A_{1}$ to $A_{4}$ cytoplasms.

The lack of differential restoration patterns, however, does not provide conclusive evidence that the CMS sources involved are necessarily similar, as it is possible that the pollinator parents used in developing the testcrosses were not adequate in number and different enough in diversity to pick up the CMS differences. It is also important in such field studies that testcrosses to be evaluated are made on isonuclear A-lines to ensure that genotypic differences of the female parents are not confounded with their cytoplasmic differences in determining fertility restoration of testcrosses.

The RFLP analysis of mtDNA based on CMS-specif ic enzyme-probe combinations provides information on the similarity or dissimilarity of cytoplasms. Differences in the RFLP patterns indicate cytoplasmic differences, although such differences may arise due to mitochondrial genomic differences that may or may not have anything to do with male fertility restoration. For instance, Chhabra et al. (1998) evaluated nine pearl millet CMS sources, identified from the Large-seeded genepool of different male sterile plants. Based on RFLP patterns of mtDNA, seven cytoplasmic groups were identified. A field study of male fertility restoration of testcrosses, developed on five of these (in isonuclear genetic background), however, grouped three sources along with $\mathrm{A}_{1}$ system and two with the $\mathrm{A}_{4}$ CMS system (K.N. Rai, unpublished). In sorghum, hybrids of three $\mathrm{A}_{4} \mathrm{CMS}$ sources (Guntur, VZM and Maldandi) had a similar male fertility restoration pattern and were designated as an $\mathrm{A}_{4}$ CMS system. RFLP patterns of mt DNA of these three sources, however, revealed them to be different from each other (Sivaramakrishnan et al., 1997). Thus, both traditional restoration pattern study and molecular approach are required to provide a conclusive evidence of whether the new CMS sources differ among themselves as well as from the existing ones.

Diversif ication of CMS sources is an important consideration in rice too, to avoid any potential risk of breakdown to any serious disease or pest. Virmani and Shinjyo (1988) mentioned several CMS sources, but it is not clear whether all these are distinct from each other. So far, about $95 \%$ of the hybrids commercialized in China and elsewhere possess only one type of cytoplasm, i.e. WA (Brar et al., 1998). CMS-WA cytoplasm gives stable CMS lines for which high frequency of restorers are available. Efforts have been made to identify new sources of cytoplasm from wild species belonging to AA genome species, 
eg. O. nivara, O. rufipogon, and O. perennis. Two CMS lines have been developed at IRRI from interspecific hybridization and substitution backcrossing (Dalmacio et al., $1995 ; 1996)$. One line IR 66707A has the cytoplasm of $O$. perennis and the nuclear genome of IR 64. Another line, IR 69700A has the cytoplasm of $O$. glumaepatula with nuclear genome of IR64. At the Directorate of Rice Research, Hyderabad, sources of male sterile cytoplasms were identified from accessions of $O$. nivara and $O$. rufipogon, and using these, six new CMS lines were developed that could be grouped into four classes (Hoan et al., 1997; Brar et al., 1998). Two CMS lines Pusha A and Mangala A with MS $577 \mathrm{~A}$ cytoplasm from $O$. rufipogon have also been developed. However, effective restorers for these are yet to be identified.

At the Central Rice Research Institute, Cuttack, new CMS sources have been identified from improved lines like Kalinga 1, V20B and Lalruma. Although many restorers have been identified for Kalinga 1 cytoplasm, only one restorer each has been identified for V20B and Lalruma cytoplasms.

\section{Utilization}

CMS utilization in breeding hybrid cultivars involves development and maintenance of seed parents (female parents and their maintainers) and male parents. The latter should have an additional trait of fertility restoration ability, if hybrids are developed for grain production. Depending on the type of hybrids envisaged and possible, both seed parents as well as restorer parents could be either inbred lines (A-line, B-line and R-line) or heterozygous and heterogeneous populations (male-sterile, maintainer and restorer population) in cross-pollinated crops. We shall, however, confine ourselves to single-cross grain hybrids produced by crossing an inbred male sterile line (A-line) with a restorer line (R-line).

\section{Potential CMS Sources}

Although several CMS systems have been identified in several crops, essentially only one CMS system is being mostly used on large-scale development of commercial hybrids [e.g., Texas CMS system in maize, (but abandoned later), $\mathrm{A}_{1} \mathrm{CMS}$ system in sorghum and pearl millet, and WA CMS system in rice]. This may have largely to do with the practical concern that an effective CMS utilization strategy entails parallel research and development efforts for both seed parents as well as restorer parents. Thus, several established restorers of the existing commercial CMS system may become obsolete due to their inability to restore male fertility in hybrids of new CMS systems. In addition to fertility restoration, other problems associated with the use of alternate CMS systems include stability of male sterility, extent of heterosis for economic traits and ease with which these male-steriles can be identified from male fertiles in the field. All these should be analyzed to make a rational judgment about CMS diversification. Often such analyses are not carried out, leaving new useful CMS systems unused or under-used.

In sorghum, as indicated earlier, $\mathrm{A}_{1}$ cytoplasm is more stable than other alternative cytoplasms, and restorer frequency with $\mathrm{A}_{1} \mathrm{CMS}$ is higher than with others. The heterosis 
estimates reported for grain yield in $\mathrm{A}_{1} \mathrm{CMS}$ system have varied. For example, the Indian National Program Testing results showed that the standard heterosis with $\mathrm{A}_{1} \mathrm{CMS}$ system for grain yield ranged from 18 to $31 \%$ in the rainy season, and from 19 to $29 \%$ in the post-rainy season during the years 1999 and 2000. The heterobeltiosis estimates in the same studies ranged from 15 to $26 \%$ in the rainy season and from 1.5 to $11 \%$ in the post-rainy season. Siddiq et al. (1993) reported that heterobeltiosis was $38 \%$ for grain yield in rainy season. Similar studies with alternative CMS systems are limited.

Comparison of heterosis with $\mathrm{A}_{1} \mathrm{CMS}$, which is commonly used, with those obtained on other systems will be useful. Senthil et al. (1998) reported that the $A_{1}$ CMS system in sorghum produced higher number of heterotic combinations than $\mathrm{A}_{2}, \mathrm{~A}_{3}$ or $\mathrm{A}_{4}$ systems. Kishan and Borikar (1989a) observed that $A_{2}$-based hybrids had larger grains and higher yields than $\mathrm{A}_{1}$ - and $\mathrm{A}_{4}$-based hybrids. Based on testing 15 hybrids derived from three isonuclear male-sterile lines and five common restorers, the $\mathrm{A}_{4}$-based hybrids were found inferior to others for grain yield in the rainy season. However, in another study, Kishan and Borikar (1989b) noticed that $\mathrm{A}_{4}$-based hybrids had higher grain yield and larger grain size than $A_{1}$ hybrids during the post-rainy season. Murthy (1986) observed that the frequency of segregation of plants for tall and dwarfs conformed to the known theory that short height is controlled by four recessive non-linked genes in crosses of two dwarf isocytoplasmic lines carrying $\mathrm{A}_{1}$ cytoplasm and two tall tropical landraces (IS 2317 and IS 35613). In the crosses of dwarf isocytoplasmic lines with the $A_{2}$ cytoplasm and two landraces, the segregation pattern of dwarf and tall plants deviated significantly from the four gene theory, indicating the effect of $\mathrm{A}_{2}$ cytoplasm on plant height. Considering the restoration frequency and hybrid performance, it is advantageous to use $\mathrm{A}_{2} \mathrm{CMS}$ system among the alternative cytoplasms available in sorghum. Accurate comparisons of CMS systems are only possible if the hybrids are developed from crosses between isonuclear. lines and common restorers. The above studies, however, did not involve such materials. Nevertheless, $A_{2} C M S$ system is not popular, as the anthers in $A_{2}$ male-steriles, unlike the $A_{1}$ male-steriles, mimic the fertile or maintainer lines and lead to difficulties in monitoring the purity of hybrid seed production. Only one hybrid based on $\mathrm{A}_{2} \mathrm{CMS}$ system has been released so far (in China) for commercial cultivation in the world.

In rice, CMS line IR 66707A having cytoplasm of O. perennis (Acc.104823) and nuclear genome of IR 64 has been subjected to molecular analysis. The results confirmed that it is different from WA source. Molecular characterization of mitochondrial genome of rice lines of WA origin has also been carried out by Seth et al. (1996). Research is underway to use polymorphism in male-sterile genes and in the expression of male sterility to differentiate maintainers and restorer lines, as also to distinguish WA cytoplasm from Chinsurah boro II cytoplasm.

\section{Seed Parents Development}

Development of maintainers is an important aspect of seed parents development and it encompasses various issues, such as what characters to consider in B-lines, when and how 
to test for combining ability and when to initiate their conversion into A-lines. But these are outside the scope of our paper, and hence will not be presented here. Rather, we shall confine ourselves to issues related to utilization of a specific CMS system and cytoplasmic diversification of A-lines.

During the process of conversion of a B-line into an A-line with a given cytoplasm, it is important to ensure that all the plants in the $\mathrm{F}_{1}$ and backcross progenies are fully sterile. Occurrence of partial sterility (i.e., very low degree of seedset under selfing) in plants in the initial generations is an indication that either the CMS system itself has a problem of poor sterility induction (as in the case of the $\mathrm{A}_{2}$ and $\mathrm{A}_{3} \mathrm{CMS}$ systems in pearl millet), or that the specific $\mathrm{B}$-line itself is a poor maintainer.

If the latter is true, then a wider search among inbred lines should lead to the identification of good maintainer lines. In completely self-pollinated crops like rice, any maintainer line which does not of fer $100 \%$ sterility from early generation itself in wet and dry seasons, should not be converted into CMS line and used in hybrid development. Another situation has been found to be very common in crops like rice, where no selection for maintainer or restorer is being done by the conventional breeders. One may find fertile, sterile and partially sterile plants to occur in the $F_{1}$ and backcross progenies, but all sterile plants neither shed any pollen nor do they set any seed under selfing. In general, this is an indication of residual heterozygosity at loci responsible for male sterility, and it should be first noticeable in the $\mathrm{F}_{1}$ itself, discounting any role of contamination in the succeeding (backcross) generations. Should this situation arise, resort should be made to making paired crosses between sterile plants of $F_{1}$ (or backcross generations) and the recurrent parent (B-line), and using the selfed seed of the B-line for backcrossing in the subsequent generation. Two generations of this backcross scheme should normally lead to fully sterile and stable backcross progenies. Plant-to-plant backcrossing coupled with testing the male-sterile line for stability has been used successfully at ICRISAT to develop stable male-sterile lines with $\mathrm{A}_{1} \mathrm{CMS}$ system, whenever fertility segregation is found. In some cases, segregation for fertility (rather occurrence of pollen shedder) may continue longer and for ever (as in case of male sterile line 834A in pearl millet), requiring exclusion of such lines from the conversion programme as early as possible.

Utilization of alternative CMS sources would require complementary efforts in developing corresponding restorers. Because such activities do not take much resources, new and alternative CMS sources should be used, only if they provide some overall advantage in terms of breeding efficiency and A-line maintenance. Until that has been demonstrated, the only larger interest they serve is their availability as standby in case the CMS system under commercial use succumbs to some unforeseen disease or insect pest.

Commercial rice hybrids released in India, Vietnam, and Philippines are based on CMS lines derived from WA cytoplasm. Attempts are being made to breed A-lines with more than one cytoplasm, to reduce the risk of genetic vulnerability. Many programmes in various countries are utilizing particularly $\mathrm{A}_{1} \mathrm{CMS}$ systems in sorghum and pearl millet in 
developing commercial hybrids. In pigeonpea, the systems are yet to be operationalized and it is likely that both the sources, $C$. sericeus or $C$. scarabaeoides may work. In maize, (1) Texas and the other CMS systems are associated with yield reduction and susceptibility to diseases in hybrids, and (2) the detasseling system lends itself to produce hybrids cheaply on a large scale, and (3) just lines can be developed faster than CMS lines. Therefore, the detasseling method involving high yielding inbred lines is used widely in hybrid production.

\section{Seed Parents Maintenance}

Occurrence of low frequency of pollen shedders in A-lines is not uncommon, although it varies a great deal with crops, CMS systems, and seed production season. It is significant to note that male sterility makes the lines more prone to contamination with foreign pollen, although the extent of it is determined by several factors such as isolation distance, wind and insect borne pollen load, pollen viability and genotype. For instance, pearl millet produces profuse pollen, which are robust by nature and can remain viable for more than a day at normal room and air temperature below $38^{\circ} \mathrm{C}$. This creates conditions for greater contamination of A-lines in pearl millet, requiring that even breeders and technicians do not move freely from one seed production field to the other on the same day. However, in other crops such as sorghum, pollen is viable for 1-2 $\mathrm{h}$ at room temperature and hence there are less chances for contamination. On the other extreme, pollen viability in rice lasts only 5-10 minutes. The purity of seed parents in this crop can well be maintained by keeping recommended isolation distance of about 250 meters.

Regardless of the care taken to prevent contamination with foreign pollen, an A-line does produce pollen shedders, and these plants are morphologically identical to those of the counterpart B-line. Such pollen shedders arise from mutation, discounting mechanical mixture from the B-line. Their frequency may vary depending on the cytoplasm, the nuclear genetic background, and the environmental factors. Also, mutation giving rise to these pollen shedders, which are called fertile revertants, may occur either in the cytoplasm or in the nucleus. In pearl millet and sorghum, a majority of the mutations producing fertile revertants are in the cytoplasm, in which case they genetically resemble the counterpart B-lines. In such a situation, maintenance of the purity of A-lines is an easy task provided these fertile revertants are rogued out of the A-line rows any time before harvesting. The roguing is easier at the time of flowering, when the fertile plants can be more easily distinguished from the sterile ones. In rice, B-lines flower 4-5 days earlier than A-lines and they can be rogued out easily before flowering. If a nuclear gene mutation (from $\mathrm{rf}$ to $\mathrm{Rf}$ allele) is the cause of reversion to male fertility, then the situation becomes more complicated, in that any contamination of the A-line with B-line from this plant will lead to a spread of the Rf allele in the lines. Carriers of this allele in the A-line cannot be detected until flowering when they shed pollen (by which time they would already have contaminated the A-line), while such carriers in the B-line cannot be detected unless evaluated for their test-cross performance. In this case, both A-line and 
B-line will have to be purified through paired crossing and test-cross evaluation for male sterility for two consecutive generations. Bulking the selfed seed of those B-line rows that produced fully sterile test-cross progenies will reconstitute the B-line. A similar bulking of the seed of plant-by-plant crosses produced between those B-line and test-cross rows will reconstitute the A-line.

A diversified (nuclear genes) set of seed parents have been developed in sorghum and pearl millet at ICRISAT and in national programs in the USA, China, India and Australia u sing the $\mathrm{A}_{1} \mathrm{CMS}$ systems. In rice, a large number of male-sterile lines have been developed in programs at IRRI, China and India.

\section{Restorer Parents Development}

Identification of promising restorer lines with respect to agronomic and adaptation traits and high general combining ability for grain yield is an important breeding activity. Equally important is genetic improvement of existing restorer lines for these traits. But these are outside the scope of this paper and hence will not be presented here. A situation may arise where an inbred line has been found to have produced a high-yielding, but a completely or partially male-sterile hybrid. This is likely to occur more within those CMS systems for which there is low frequency of restorers in the general breeding materials, viz. $A_{5}$ CMS system in pearl millet and $A_{3}$ CMS system in sorghum. In such cases, the most effective approach is to identify best restorer source (s) and undertake backcross transfer of restorer gene(s) in these lines. Considering the paucity of restorers of the $\mathrm{A}_{4}$ and $A_{5} C M S$ systems in pearl millet and $A_{2}, A_{3}$ and $A_{4} C M S$ system in sorghum, a backcross breeding scheme (Fig. 1) for development of restorers of these two CMS systems was recently initiated at ICRISAT. In this breeding scheme, an A-line is crossed with a restorer gene donor, which produces a male-fertile $F_{1}$ hybrid. This $F_{1}$ is crossed (as a female parent) with that inbred line (as a recurrent parent) which is to be converted into a restorer version. The three-way hybrid so produced will segregate for fertile and sterile plants (in the sterile cytoplasmic background). In case there is segregation for varying fertility levels, the most fertile plants are selected and crossed (again as a female) with the recurrent parent to produce $\mathrm{BC}_{1}$. This process of selection of most fertile plants and crossing them with the recurrent parent is continued until $\mathrm{BC}_{7}$ or till the $\mathrm{BC}$ progeny becomes indistinguishable from the recurrent parent. After the final backcross, 4-5 most fertile plants should be selected and selfed to produce $\mathrm{BC}$-derived $\mathrm{F}_{2}$ progenies, which should be grown head-to-row. All will segregate for both fertile and sterile plants. Some of the fertile plants will be homozygous for restorer gene (s), and hence will produce uniformly fertile $\mathrm{F}_{3}$ progenies. Bulked seed from the selfed plants of these progenies will produce restorer version of the recurrent parent (essentially a non-restorer line).

A diversified set of restorers for $A_{1}$ and $A_{2}$ and the common restorer for $A_{1}$ and $A_{2}$ are developed at ICRISAT and in other national programs in sorghum. Similarly, a large number of restorers for $\mathrm{A}_{4}$ and $\mathrm{A}_{5} \mathrm{CMS}$ systems in pearl millet are being developed at ICRIS AT. However, work is at initial stage in developing restorers for the two CMS 


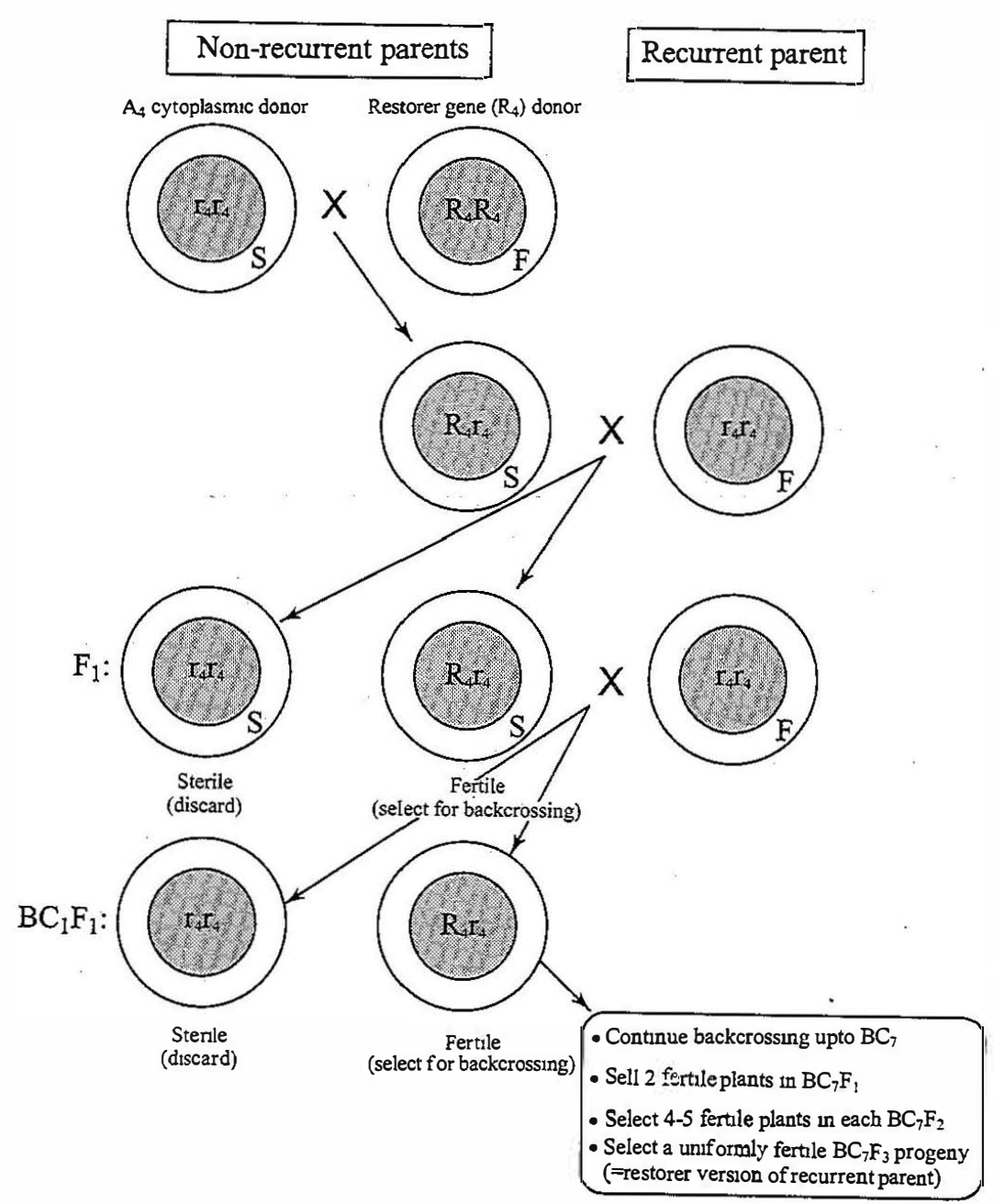

Fig. 1. Schematic back-cross procedure for breeding restorer lines of $\mathbf{A}_{4}$ cytoplasmic-nuclear male sterility

systems in pigeonpea. Several restorers in rice have been developed for CMS lines derived from WA CMS system in IRRI, and national programs in China and India.

The maintenance of genetic purity of parents is an important problem in large scale seed production of parental lines and hybrids. Conventionally, seed purity of hybrids and parental stocks is done by morphological assay called "Grow Out Test" (GOT). Isozymes, and more recently micro satellite DNA markers, are being used in rice as a substitute to GOT (Sarma et al. 2001).

\section{Hybrid Seed Production}

In most crops, the four key elements in hybrid seed production are: $(i)$ isolation distance, (ii) removing off types, (iii) flowering synchrony between A- and R-lines and (iv) A:R lines ratio. In crops like rice, exsertion of panicles from leaf sheath and angle and duration of flower opening are the important factors. Isolation distance is determined by the breeding system of the crop and the class of seed. Thus, for the highly cross-pollinated pearl millet, recommended isolation distance is $1000 \mathrm{~m}$ for breeder and foundation seed of parental lines and $200 \mathrm{~m}$ for the certified seed production of hybrids. The isolation 
distance is $400 \mathrm{~m}$ for hybrid parents and $200 \mathrm{~m}$ for hybrids for producing breeder and foundation seed in sorghum. In all crops, it is highly essential to remove the off-types before flowering in parents and the pollen shedders at flowering in the female parents. For rice, the isolation distance should be $150 \mathrm{~m}$ for breeder and foundation seed and $100 \mathrm{~m}$ for certified seed production.

The large flowering synchrony problem arises, but only in the case of certified hybrid seed production, for two reasons: (i) A- and R-lines of the highest yielding hybrids may have different flowering time (and this is not uncommon), and (ii) both parents that appeared to be synchronous for flowering in the environments where they were bred, may display different flowering time in some of the seed production environment due to differences in their sensitivity to climatic factors such as temperature and photoperiod. Flowering differences of up to 20 days have been effectively managed in pearl millet by staggered sowing of A- and R-lines. In self-fertilized crops like sorghum and rice, hybrids with A- and R-lines differing in flowering by more than 10 days are discouraged. In sorghum, differences in flowering of A- and R-lines up to 10 days have been managed with staggered planting and/or with transplanting by several seed companies.

In case of rice, a CMS line takes 4-6 more days to flower than that of the B-line, on account of cytoplasmic effects. Since transplanting is commonly followed in rice, flowering synchrony of A- and B-lines can be managed by sowing A-line 4-6 days earlier than B-line in nursery and transplanting of both A- and B-lines can be done on the same day in the main field.

In hybrid seed production of rice, the difference between A- and R-lines of currently cultivated hybrids is 4-10 days in India. A difference of 7-10 days between A- and R-line has ideally been managed by many companies. Even 15-20 days difference can be managed through the current technology in India. In countries like China, a difference of up to 40 days in A- and R-line has been very well managed by sowing and transplanting of A- and R-line on different dates on one hand and managing synchrony of flowering through various management practices on the other.

The parental lines ratio will also depend on the breeding system of the crop, mode of pollination and pollen-producing ability. In case of pearl millet that generally produces profuse pollen, which become wind borne, the recommended ratio is $4: 2$ or $6: 2$ between A- and B-lines and 4:1 or 6:1 between A- and R-lines. If R-line is very vigorous and has height much taller than A-line (as in case of the parental lines of hybrid ICMH 451), farmers have found even 10-12A:1R ratio most economical. In sorghum, pollination is by wind and generally the R-lines produce profuse pollen. A- and B-lines flower almost simultaneously. The recommended ratio, as in pearl millet is $4: 2$ or $6: 2$ between A- and B-lines, and 4:1 or 6:1 between A- and R-lines, and these are followed generally in India and China. However, in countries like the USA, Australia, Colombia, Brazil, 8:1 or 12:1 ratio between A- and R-lines, is followed for hybrid seed production. In rice, the parental line ratio of 8-10:2 has been found to be ideal in India but in countries like China, where 
specific parental lines have been developed for hybrids, i.e. A-lines have been bred with very high outpollination potential and $\mathrm{R}$-line with high pollen production potential, a ratio of from $12: 2$ to $16: 2$ is commonly followed. In order to enhance panicle exsertion from leaf sheath and stigma from lemma and palea, seed producers in China use $\mathrm{GA}_{3}$ up to 200 $\mathrm{g} \mathrm{ha}^{-1}$. In India, GA3 dose of up to $50-60 \mathrm{~g} \mathrm{ha}^{-1}$ is recommended, on account of high cost of $\mathrm{GA}_{3}$. Technological innovations to lower the cost of hybrid seed production have been given by Mao et al. (1998).

In pearl millet and sorghum, where A-line and hybrid seed production is relatively easy, seed yields of 1.5-2.0 $\mathrm{t} \mathrm{ha}^{-1}$ have been reported on CMS lines. Based on several experimental studies carried out on seed technological aspects in rice, package of practices have been developed for seed production of hybrids and CMS lines multiplication in China and in India (Virmani et al., 1997). Seed yield of 1.5-2.0 $\mathrm{tha}^{-1}$ of A-lines and hybrids can be obtained in India. Seed yields can be further enhanced through increasing the outcrossing potential of parental stock and refinement of seed production technology.

\section{References}

Anand Kumar K., Jain R.P., and Singh S.D. 1983. Downy mildew reactions of pearl millet lines with and without cytoplasmic male sterility. Plant Dis., 67: 663-665.

Anonymous. 1998. Hybrid Rice Progress Report 1989-98. ICAR project on promotion of Research and development efforts on hybrids in selected crops - Rice. Directorate of Rice Research, Rajendranagar, Hyderabad, India. 131 pp.

Appa Rao S., Mangesha M.H. and Rajagopal Reddy C. 1989. Development of cytoplasmic male-sterile lines of pearl millet from Ghana and Botswana germplasm. Pp 817-823. In: Perspectives in Cytology and Genetics, (eds.) G.K. Manna and U. Sinha, All India Congress of Cytology and Genetics, Kalyani Publishers, India.

Athwal D.S. 1961. Recent developments in the breeding and improvement of bajra (pearl millet) in the Punjab. Madras Agric. J., 48: 18-19 (Abstract).

Athwal D.S. and Virmani S.S. 1972. Cytoplasmic male sterility and hybrid breeding in rice. In: Rice Breeding. pp. 615-620. Int. Rice Res. Inst. Manila, Philippines.

Burton G.W. 1958. Cytoplasmic male-sterility in pearl millet [Pennisetum glaucum (L.) R.Br.]. Agron. J., 50: 230.

Brar D.S., Zhu Y.G., Ahmed M.I., Jachuck P.J. and Virmani S.S. 1998. Diversifying the CMS system to improve the sustainability of hybrid rice technology. In: Hybrid Rice Technology, p. 443. Proc. 3rd Intl. Symp. on Hybrid Rice, 14-16 Nov, 1996, Hyderabad, India.

Carnhan H.L., Erickson J.R., Tseng S.T. and Rutger J.N. 1972. Outlook for hybrid rice in USA. In: Rice Breeding, pp. 603-607, Int. Rice Res. Inst., Manila, Philippines.

Chhabra A.K., Rai K.N., Khairwal I.S., Sivaramakrishnan S. and Hash C.T. 1998. Mitochondrial DNA-RFLP analysis distinguishes new CMS sources in pearl millet (Pennisetum glaucum (L.) R.Br.). J. Plant Biochem. and Biotech., 7: 85-92.

Dalmacio R.D., Brar D.S., Ishii T., Sitch L.A., Virmani S.S. and Khush G.S. 1995. Identification and transfer of a new cytoplasmic male sterility sources from Oryza perennis into indica rice (Oryza sativa L.) Euphytica, 82: 221-225. 
Dalmacio R.D., Brar D.S., Virmani S.S. and Khush G.S. 1996. Male sterile line in rice (Oryza sativa) developed with $O$. glumaepatula cytoplasm. IRRN., 21: 22-23

Devi D.R. and Murthy U.R. 1993. Genotype environment interaction in tapetal development $\mathrm{A}_{2}$ based sorghum genotypes. Sorghum Newsl., 34: 41.

Downes R.W. and Marshall D.R. 1971. Low temperature induced male sterility in Sorghum bicolor. Aust. J. Exp. Agric. Anim. Husb., 11: 352-356.

Duncan R.R., Bramel-Cox P.J. and Miller F.R. 1991. Contributions of introduced sorghum germplasm to hybrid development in the USA. In: Use of plant introductions in cultivar development. Part 1. (eds.) Shands H.L. and L.E. Wiesner, Proceedings of a symposium sponsored by Division C-1 of the Crop Sci. Society of America in Las Vegas, Nevada, USA, pp. 69-102, Crop Sci. Society of America, Madison, Wisconsin, USA.

Duvick D.N. 1965. Cytoplasmic pollen sterility in corn. Adv. Genet., 13: 1-52.

Ganesan K.N., Thiyagarajan K. and Rangaswamy M. 1998. Effect of minor genes in restoration fertility in CMS lines of rice. International Rice Res. Notes., 23: 9.

Govindraj K. and Virmani S.S. 1988. Genetics of fertility restoration of WA type cytoplasmic male-sterility in rice. Crop Sci., 28: 787-792.

Hanna W.W. 1989. Characteristics and stability of a new cytoplasmic-nuclear male-sterile source in pearl millet. Crop Sci., 27: 1457-1459.

Hoan N.T., Sarma N.P. and Siddiq E.A. 1997. Identification and characterization of new sources of cytoplasmic male sterility in rice. Pl. Breed., 116: 547-551.

House L.R. 1985. A Guide to Sorghum Breeding. (2nd Edn.). International Crops Research Institute for the Semi-Arid Tropics (ICRISAT), Patancheru 502 324, A.P., India. 206 pp.

Kishan A.G. and Borikar S.T. 1989a. Genetic relationship between some cytoplasmic male sterility systems in sorghum. Euphytica, 42: 259-269.

Kishan A.G. and Borikar S.T. 1989b. Comparative performance of Maldandi vs Milo cytoplasm in sorghum. J. Maharashtra Agric. Univ., 14: 192-195.

Kumari S.L., Mahadevappa M. and Kulkarni R.S. 1998. Fertility restoration study in four WA CMS lines of rice. Int. Rice Res. Notes, 23: 9.

Li Zhengyon. 1980. Dian type hybrid rice. Yuan People's Press, China.

Li Z.J., Zhang K.T., Oing Y.X. and Xo J.X. 1981. Effect of climate on male sterility in sorghum. Agron. Sinica, 7: 129-133.

Lin S.C. and Yuan L.P. 1980. Hybrid rice breeding in China. In: Innovative approaches in Rice Breeding. pp. 35-51, Int. Rice Res. Inst. Manila, Philippines.

Lin S.C. and Ming S.K. 1991. Rice varieties and their geneology in China. Shanghai Scientific and Technical Publishers, Shanghai, China.

Lin Z. and Zhu Y. 1988. Rice male-sterile cytoplasm and fertility restoration. In: Hybrid Rice. pp. 85-102, Int. Rice Res. Inst. Manila, Philippines.

Madhava Menon P.M. 1959. Occurrence of cytoplasmic male- sterility in pearl millet (Pennisetum typhoides Stapf \& Hubb.), Curr. Sci., 28: 165-167.

Mao C.X., Virmani S.S. and Ish Kumar. 1998. Technological innovations to lower the costs of hybrid seed production. In: Advances in hybrid rice technology. Proceedings of 3rd International Symposium on Hybrid Rice. November 14 -16, 1996 pp. 111-128.

Marchais L. and Pernes J. 1985. Genetic divergence between wild and cultivated pearl millets (Pennisetum typhoides). I. Male sterility. Z. Pflanzenzuchtg, 95: 103-112. 
Maruyama K., Araki K. and Keto H. 1991 Thermosensitive genetic male sterility induced by irradiation. In: Rice Genetics II, pp.227-232, Int. Rice Res. Inst. Manila.

Maunder A.B. 1972. Objectives and approaches to grain and forage sorghum improvement in the Americas. In: Sorghum in Seventies, (eds.) N. Ganga Prasada Rao and L.R. House. Oxford and IBH publishing Co., New Delhi, India. pp. 60-99.

Murthy U.R. 1986. Effect of A2 cytoplasm on the inheritance of plant height in temperate $\times$ tropical sorghum crosses. Sorghum Newsl., 29: 77.

Nagur T. and Menon P.M. 1974. Characterization of male sterility-inducing cytoplasms in sorghum. Sorghum Newsl., 17: 18.

Pan Xigan. 1982. Analysis of the effect of cytoplasm on heterosis. Agricultural Science \& Technology, Jiangxi.

Pradhan S.B. and Jachuck P.J. 1998. Krishna CMS line in the background of four different cytoplasmic sources in rice. Int. Rice. Res. Notes, 23: 6.

Pradhan S.B., Ratho S.N. and Jachuck P.J. 1990. New sources of cytoplasmic-genetic male-sterility in cultivated indica rices. Euphytica, 48: 215-218.

Rai K.N., Andrews D.J. and Suresh B abu V. 1985. Inbreeding depression in pearl millet composites. Z. Pflanzenzuchtg, 94: 201-207.

Rai K.N. and Hash C.T. 1993. A new source of cytoplasmic-nuclear male-sterility in pearl millet. Cereals Program, ICRISAT. Annual Report (1992).

Rai K.N. 1995. A new cytoplasmic-nuclear male-sterility system in pearl millet. Plant Breed., 114: 445-447.

Rai K.N. and Thakur R.P. 1995. Ergot reaction of pearl millet hybrids affected by fertility restoration and genetic resistance of parental lines. Euphytica, 83: 225-231.

Rai K.N. and Thakur R.P. 1996. Smut reaction of pearl millet hybrids affected by fertility restoration and genetic resistance of parental lines. Euphytica, 90: 31-37.

Rai K.N., Andrews D.J., Rao A.S., Rajewski J.F. and Du R.H. 1999. Restorer sources of As cytoplasmic-nuclear male sterility in Pennisetum germplasm and its implications in pearl millet hybrid breeding. Plant Genetic Resources Newsletter, 1999, 120 : 20-24.

Reddy Belum V.S. 1992. Varietal improvement: Three-way single cross hybrids. In: Annual Report 1991, pp. 66-67, International Crops Research Institute for the Semi-Arid Tropics (ICRISAT), Patancheru 502 324, Andhra Pradesh, India.

Reddy Belum V.S. 1997. Production of sorghum hybrids. In: Training Manual on Development of Cultivars and Seed Production Techniques in Sorghum and Pearl Millet, (eds.) Singh, Faujdar, K.N. Rai, Belum V.S. Reddy \& B. Diwakar. pp. 31-33, International Crops Research Institute for the Semi-Arid Tropics (ICRISAT), Patancheru 502 324, Andhra Pradesh, India.

Reddy Belum V.S. and Stenhouse J.W. 1994. Sorghum improvement for the semi-arid tropic region: past, current and future research thrusts in Asia. Punjabrao Krishi Vidyapeeth Res. J., 18: $155-170$.

Sahadevan P.C. and Namboodri K.M.N. 1963. National outcrossing in rice. Proc. Indian Acad. Sci., Sect. B., 58: 176-185.

Sampath S. and Mohanty H.K. 1954. Cytology of semi sterile rice hybrid. Curr. Sci., 23: 182-183. 
Sarma N.P., Sundaram R.M., Thirumurugan T., Viraktamath B.C., Ramesha M.S., Yashitola J. and Sonti R. 2001. DNA marker technology for purity assessment of rice hybrids and parental stocks. ICAR Science and Technology Newsletter, 7: 1-2.

Saxena K.B. 2001a. Heterosis breeding in Pulses - Problems and Prospects, pp. 61-72. In: Pulses for Sustainable Agriculture and Nutritional Security. (eds.) Ali, Masood, Chaturvedi S.K. and Gurha S.N. Indian Institute of Pulses Research, Kanpur.

Saxena K.B. 2001b. Prospects for hybrid pigeopea. Paper presented at National Symposium on Pulses and Oil Seeds on sustainable agriculture. Tamil Nadu Agricultural University, Coimbatore. 29-31 July 2001.

Scheifele G.L, Whitehead G.W. and Rowe C. 1970. Increased susceptibility to southern leaf spot (Helminthosporium maydis) in inbred lines and hybrids of maize with Texas male-sterile cytoplasm. Plant Dis. Rep., 54: 501-503.

Schertz K.F. and Ritchey J.R. 1977. Cytoplasmic-genetic male-sterility systems in sorghum. Crop Sci., 18: 890-893.

Schertz K.F. and Pring D.R. 1982. Cytoplasmic sterility systems in sorghum. In: Proceedings of an International Symposium on Sorghum in the Eighties, (eds.) Rao, N.G.P. \& L.R. House. pp. 373-383, International Crops Research Institute for the Semi-Arid Tropics (ICRISAT) center, Patancheru 502 324, Andhra Pradesh, India.

Schertz K.F., Sotomayor-Rios A. and Torraco-Cardona S. 1989. Cytoplasmic-nuclear male-sterility opportunities in breeding and genetics. Proceedings of the Grain Sorghum Research and Utilization Conference, 16: 175-186.

Schertz K.F., Sivaramakrishnan S., Hanna W.W., Mullet J., Yi Sun, Murty,U.R., Pring D.R.,- Rai K.N. and Reddy Belum V.S. 1997. Alternate cytoplasms and apomixis of sorghum and millet. In: Proceedings of the International Conference on Genetic Improvement of Sorghum and Pearl Millet, 22-27 September 1996, Holiday Inn Plaza, Lubbock, Texas, USA. pp.213-223, Texas Agricultural University

Scheuring J.F. and Miller F.R. 1978. Fertility restorers and sterility maintainers to the milo-kafir genetic cytoplasmic male sterility system in the sorghum world collection, Misc. Publ., Texas A\&M Agricultural Experiment Station, College Station, Texas, USA, 1367:47 pp.

Senthil N., Ramasamy P. and Khan A.K.F. 1998. Fertility restoration and heterosis involving different cytoplasms in sorghum [Sorghum bicolor (L.) Moench] hybrids. J. Genet.\& Breeding, 52: 339-342.

Seth P., Sane A.P., Nath P. and Sane P.V. 1996. Molecular characterization of mitochondrial genomes of rice lines containing wild abortive (WA) male-sterile and fertile cytoplasms. $J$. Plant. Biochemistry \& Biotechnology, 5: 75-82.

Sharma H.C., Vidyasagar P., Abraham C.V. and Nwanze K.F. 1994. Effect of cytoplasmic male-sterility in sorghum on host plant interaction with sorghum midge, Contarinia sorghicola. Euphytica, 74: 35-39.

Shen Xiaobang. 1982. Preliminary study on the genetic effect of rice sterile cytoplasm. I. The effect of sterile cytoplasms on the agronomic characters of hybrid rice. J. Huazhong Agric. Coll., 3.

Shinjyo C. and Omura T. 1966. Cytoplasmic male sterility in cultivated rice, Oryza sativa L.I. Fertiles of $F_{1}, F_{2}$, and offsprings obtained from their mutual reciprocal backcrosses and segregation of completely male sterile plants. Jpn. J. Breed., 16: 179-180. 
Shinjyo C. 1969. Cytoplasmic-genetic male-sterility in cultivated rice Oryza Sativa L. II. The inheritance of male sterility. Jpn. J. Genet., 44: 149-156.

Siddiq M.A., Madrap I.A. and Ambekar S.S. 1993. Heterosis studies in sorghum. In: The Indian Journal of Genetics \& Plant Breeding. Abstract of papers. pp. 123-124. National symposium on Plant Breeding Strategies for India 2000 A.D. and Beyond, Dec 25-27, 1993.

Sivaramakrishnan S., Seetha K. and Reddy Belum V.S. 1997. Characterization of the $A_{4}$ cytoplasmic male-sterile lines of sorghum using RFLP of mt DNA. Euphytica, 93: 301-305.

Stephens J.C. and Holland P.F. 1954. Cytoplasmic male sterility for hybrid sorghum seed production. Agron. J., 46: 20-23.

Virk D.S. 1988. Biometrical analysis in pearl millet: a review. Crop Improv., 15: 1-9.

Virmani S.S., Govind Raj K., Casal C., Dalmacio R.D. and Aurin P.A. 1986. Current knowledge and outlook on cytoplasmic-genetic male-sterility and fertility restoration in rice. In: Rice Genet., pp. 633-647, Int. Rice Res. Inst., Manila, Philippines.

Virmani S.S. and Shinjyo C. 1988. Current status of analysis and symbols for male sterile cytoplasm and fertility restoring genes. Rice Genet. Newsl., 5: 9-15.

Virmani S.S. and Wan B.H. 1988. Development of CMS lines in hybrid rice breeding. In: Hybrid rice. pp. 103-114. Int. Rice Res. Inst. Manila, Philippines.

Virmani S.S. 1994. Prospects of hybrid rice in the tropics and sub-tropics. In: Hybrid Rice Technology - New Developments and Future Prospects. pp.7-20. Int. Rice Res. Inst, Los Banos, Philippines.

Virmani S.S. 1996. Hybrid Rice. Adv. Agron., 57: 377-463.

Virmani S.S., Viraktamath B.C., Casal C.L., Toledo R.S., Lopez M.T. and Manalo J.O. 1997. Hybrid Rice Breeding Manual. Int. Rice Res. Inst., Las Banos, Laguna, Philippines. P.151.

Webster O.J. and Singh S.P. 1964. Breeding behavior and histological structure of a nondehiscent anther character in Sorghum vulgare. Crop Sci., 4: 656-658.

Yadav O.P., Manga V.K. and Gupta G.K. 1993. Influence of $\mathrm{A}_{1}$ cytoplasmic substitution on the downy mildew incidence in pearl millet. Theor. Appl. Genet., 87: 558-560.

Yang Rencui. 1980. Effect of sterile cytoplasm of wild abortive rice on $\mathrm{F}_{1}$ generation $J$. Fujian Agric. Coll., 12: 14-21.

Yuan L.P. 1977. The execution theory of developing hybrid rice. Zhonggue Nongye Kexue. Chinese Agric. Sci., 1: 27-31.

Yuan L.P. 1985. A concise course in hybrid rice. Human Technological press, China. p. 168.

Yuan L.P. and Virmani S.S. 1988. Organization of hybrid rice breeding program. In: Hybrid Rice. pp. 33-37. Int. Rice Res. Inst., Manila, Philippines.

Yuan L.P, Virmani S.S. and Mao C.X. 1989. Hybrid Rice - Achievements and future outlook. In: Progress in Irrigated Rice Research. pp. 219-235, Int. Rice Res. Inst., Manila, Philippines. 